\title{
The Basic Pharmacology of Opioids Informs the Opioid Discourse about Misuse and Abuse: A Review
}

Joseph V. Pergolizzi Jr. · Jo Ann LeQuang · Garrett K. Berger •

Robert B. Raffa

Received: February 15, 2017 / Published online: March 24, 2017

(C) The Author(s) 2017. This article is an open access publication

\section{ABSTRACT}

Morphine and other opioids are widely used to manage moderate to severe acute pain syndromes, such as pain associated with trauma or postoperative pain, and they have been used to manage chronic pain, even chronic nonmalignant pain. However, recent years have seen a renewed recognition of the potential for overuse, misuse, and abuse of opioids. Therefore, prescribing opioids is challenging for healthcare providers in that clinical effectiveness must be balanced against negative outcomes-with the possibility that neither are achieved perfectly. The current discourse about the dual 'epidemics' of under-treatment of legitimate pain

Enhanced content To view enhanced content for this article go to http://www.medengine.com/Redeem/ 98F7F0607B10EAF6.

R.B. Raffa is Professor Emeritus, Temple University School of Pharmacy, Philadelphia, PA, USA .

J. V. Pergolizzi Jr. · J. A. LeQuang ( $₫)$

NEMA Research, Inc., Naples, FL, USA

e-mail: joann@leqmedical.com

G. K. Berger

College of Pharmacy, University of Arizona, Tucson, AZ, USA

\section{R. B. Raffa}

Department of Pharmacology and Toxicology, College of Pharmacy, University of Arizona, Tucson, AZ, USA and the over-prescription of opioids is clouded by inadequate or inaccurate understanding of opioid drugs and the endogenous pain pathways with which they interact. An understanding of the basic pharmacology of opioids helps inform the clinician and other stakeholders about these simultaneously under- and over-used agents.

Keywords: Opioid misuse; Opioid pharmacology; Opioids

\section{INTRODUCTION}

The inappropriate use, nonmedical use, misuse, and abuse of prescription opioid analgesics in the USA has been described as an epidemic [1]. The rate of drug overdose deaths in the USA attributable to opioids (both prescription opioid pain relievers and heroin) doubled from 2000 to 2014 [2]. The National Survey on Drug Use and Health found that in 2011, 8.7\% of Americans over the age of 12 identified themselves as current drug users, including of opioids [3]. Heroin use, which appears to be associated with prescription opioid abuse [4], presents additional challenges [5]. The economic burden of opioid misuse has been estimated to be over $\$ 78$ billion a year in the USA [6], with the additional human costs of reduced quality of life, psychological distress, social dysfunction, disordered 
familial relationships, among others [7]. Increasingly, newspapers and other media outlets report on the prescription pain reliever crisis and opioid addiction, so what was once a "medical problem" has now become a public health crisis and a major societal issue [8].

The opioid crisis is actually two crises that may be seen as dual epidemics. The first crisis is opioid abuse, in which opioids are widely prescribed and may be widely abused [9], although it is unclear if the imposition of strict opioid prescribing policies can significantly affect levels of opioid misuse [10]. The second crisis is that of uncontrolled pain. About two-thirds of the world does not have access to opioid analgesics, so that moderate to severe pain and even the very extreme pain associated with terminal cancer at end of life is not effectively treated [11-15]. So egregious was the care of patients facing excruciating pain that in 1988, the World Health Organization advocated the widespread use of oral morphine and other opioid analgesics for cancer patients [16], and pain control emerged in international conferences as a "fundamental human right" $[17,18]$. In the past decades, pain management has emerged as a clinical goal in and of itself, and pain medicine has become a recognized medical specialty, albeit one in its relative infancy.

Opioids thus present medicine, and indeed society, with a double-edged sword. On the one hand, opioid agents are crucial to managing pain in specific populations, and professional compassion demands that physicians alleviate pain when and where they can do so both effectively and safely. It may also be put forth as a laudable public health goal to restore function and productivity to patients whose painful symptoms might otherwise have disabled them. On the other hand, opioids are powerful substances that can be misused and abused with devastating individual and societal consequences. Greater clarity and scientific objectivity are needed to better understand the inappropriate use of opioids. Toward that end, we present here a concise review of opioid pharmacology with the aim of adding to the understanding of opioid misuse and abuse.

\section{Compliance with Ethics Guidelines}

This article does not contain any new studies with human or animal subjects performed by any of the authors.

\section{PAIN PATHWAYS}

The physiology of pain can help illuminate why opioids are such effective pain relievers. The current model of a representative pain pathway describes a noxious stimulus originating in the periphery (such as a blow to the hand), which is then transmitted via primary afferents to the dorsal root ganglion (DRG) and, from there, to the dorsal horn of the spinal cord. From the spinal cord, the noxious stimulus signal travels up the ascending pain pathways to the brain (e.g., the spinothalamic tract). The brain then interprets the pain signal, assigns its meaning, and initiates appropriate responses, such as moving the hand out of harm's way. The brain also sends a signal back via descending pathways that modulates the incoming signal. Hence pain-transmission signals travel upward from the spinal cord to the brain along any of several ascending pathways, and pain-modulating signals travel downward (from the brain to the spinal cord) along descending pathways (see Fig. 1).

Receptors for endogenous opioids (e.g., endorphins and enkephalins) are located in the periphery, the DRG, the spinal cord, and the brain. Opioid analgesic agents mimic the endogenous opioids and act by binding to (have "affinity" for) the 7-transmembrane G-protein-coupled opioid receptors, thereby activating them ("agonist action", "intrinsic activity"), albeit with individual differences in receptor binding and signal transduction [19]. In this way, exogenous opioids can inhibit pain signals as they travel along ascending pathways or mitigate pain via descending pain pathways. Of course, individual responses to pain can vary markedly and are colored by emotional state, past experiences, memories, genetics, and other factors [19], with the result that pain is both a physical response and a multifactorial subjective experience. 


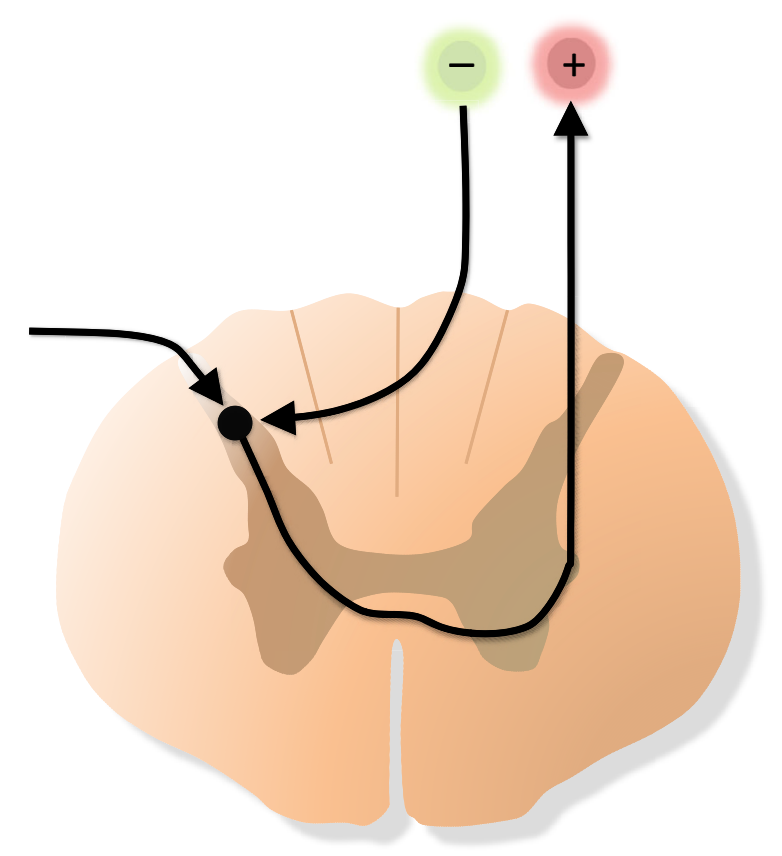

Fig. 1 Pain-transmitting $(+)$ and pain-modulating (-) signals traveling to and from the dorsal horn of the spinal cord

While nociceptive pain involves a noxious stimulus at the periphery that is interpreted as pain by the brain, neuropathic pain occurs when nerve fibers at any of the points along the pain pathway or at the periphery become injured, damaged, and/or dysfunctional or transmit signals inappropriately [20]. In that way, neuropathic pain can arise without an overt injury or noxious stimulus. While nociceptive pain and neuropathic pain are distinct clinical entities, they sometimes occur together in a condition described as multimechanistic pain.

\section{OPIOID RECEPTORS}

Three distinct opioid receptor peptides have been pharmacologically characterized. They are termed mu-opioid peptide (MOP) receptors (MORs), named for morphine; delta-opioid peptide (DOP) receptors (DORs), named for tissue of the vas deferens; and kappa-opoid peptide (KOP) receptors (KORs), named for the selective agonist ketocyclazocine [21]. The genes of each of these receptor systems have been cloned (Oprm, Oprd1, and Oprk1, respectively). All three types include seven membrane-spanning regions and are coupled to $G$ proteins that couple the receptors to intracellular effectors that transmit (transduce) pain signals. Most of the common clinically used opioid agents have the greatest affinity and intrinsic activity at mu-opioid receptors and less at delta- and kappa-opioid receptors, but they may produce some effects at the latter two receptor types, particularly at higher doses. Other factors may play an important role, such as, for example, transporter proteins that can facilitate or impede passage across the blood-brain barrier [22].

The cellular mechanisms by which opioids produce their effects are well established. All three activate inwardly rectifying $\mathrm{K}^{+}$conductance and inhibit voltage-gated $\mathrm{Ca}^{2+}$ currents. Because $\mathrm{Ca}^{2+}$ influx is required for proper vesicle function and stimulus-secretion coupling of neurotransmitter release, opioids are able to decrease the release of excitatory neurotransmitters, such as glutamate, substance $P$ and calcitonin-gene-related-peptide [23]. Activation of rectifying $\mathrm{K}^{+}$conductance hyperpolarizes neurons, making them more resistant to excitation and, in that way, raises the pain transmission threshold. Recent research suggests that $G$ protein signaling can be selectively targeted [24].

Other brain chemicals, such as monoamines, come into play. Norepinephrine (NE) generally mediates descending inhibition, that is, inhibitory pain control. Serotonin (5-hydroxytryptamine) has the paradoxical property of being both anti-nociceptive and pro-nociceptive in that it can either mediate descending inhibition of pain signals or facilitate pain signaling [25]. Crosstalk between the opioid and the monoaminergic systems permit the brain to interpret and evaluate pain (as a surrogate indication of tissue damage) yet not be overwhelmed by it (that is, not interfere with "fight or flight" responses or recovery) [26]. In this complex chemical system, signal fidelity is of prime importance.

It is worth noting here that if acute pain transitions into the more clinically challenging 
syndrome of chronic pain [27], the relative contribution of the monoaminergic system increases markedly [28]. NE-mediated pain emerges as particularly important in chronic painful conditions because the opioidergic system may lose influence due to opioid tolerance, receptor down-regulation, or opioid-induced hyperalgesia (OIH) [29]. OIH is the seemingly paradoxical condition in which prolonged exposure to opioids lowers the pain threshold [30]. In such cases, patients may obtain pain relief from mixed NE/serotonin reuptake inhibitors, such as venlafaxine, while selective serotonin-reuptake inhibitors, such as fluoxetine, may not produce clinically important pain relief [31].

In summary, opioids can inhibit pain signaling along the ascending pain pathway, exert modulatory effects on pain signals at the supra-spinal level, and modulate pain signals via the descending monoaminergic system pathways.

\section{CLASSIFICATION OF OPIOIDS}

Until recently it was believed that the various opioids (such as codeine, fentanyl, hydrocodone, hydromorphone, morphine, oxycodone, and others) comprised a single, but large, drug class. Indeed, although there are subtle differences among opioids, such as varying degrees of preferences for specific opioid receptors, they have much in common and essentially work in the same way. However, increased knowledge of drug molecules, pain mechanisms, and brain biochemistry has revealed that opioids are far more individualized than previously believed, which complicates a classification system. Some modern analgesics have both opioid and nonopioid mechanisms of action, and these become important differentiating factors in classification systems $[19,22]$. Moreover, certain transporter proteins (e.g., P-glycoprotein) can regulate the degree to which these agents pass the blood-brain barrier, which can affect in turn how the individual opioid agent is distributed through the body [32]. For example, oxycodone passes the blood-brain barrier to a greater degree than does morphine [33, 34].

\section{NOVEL CATEGORIES OF ANALGESICS}

An increasing understanding of the multiple mechanisms that can underlie pain syndromes has given rise to multimechanistic approaches to analgesia, such as the combination of an opioid with a nonopioid [35]. The emerging concept of "signaling bias" addresses the fact that subsets of the G-proteins can mediate the antinociception conferred by various opioids in different ways [36]. The emergence of these drugs is the result of an important new direction in drug development which attempts to provide the analgesic benefits of opioids while simultaneously attempting to reduce the side effects and abuse potential of conventional opioids [22].

- Buprenorphine [37] exhibits many characteristics of conventional opioids but has been found in preclinical studies to have a slow receptor dissociation kinetics which confer it with some unique characteristics $[38,39]$. There might even be a nonopioid component to buprenorphine's analgesic action [40]. While its mechanisms remain to be more fully elucidated, it must be considered to be a distinct agent with attributes markedly different from opioids such as morphine [22]. Thus, buprenorphine is generally regarded as an opioid, but one with unique characteristics [39]. Its potential for abuse is generally considered to be lower than that of such agents as oxycodone or hydromorphone although buprenorphine misuse has increased somewhat in recent years [41]. Buprenorphine has become well established in opioid maintenance [42].

- Tramadol has been demonstrated in animal models and in humans to have both opioid and nonopioid mechanisms of analgesic action [43]. The parent drug binds to the MOR with a relatively weak affinity, but its metabolite $O$-desmethyltramadol (M1) binds 
to the MOR with a much greater affinity and is likely the source of tramadol's opioid-like effects. However, tramadol produces a nonopioid analgesic effect as well, likely related to the inhibition of neuronal reuptake of NE and serotonin [44]. Tramadol has also been reported to have some anti-inflammatory activity [45]. The two mechanisms of action (opioid plus nonopioid) act synergistically with each other [46]. Furthermore, the dual mechanism of action may help explain why tramadol is generally not a well "liked" drug by abusers. It is considered to have a relatively lower potential for abuse than single-mechanism pure opioids [47]. The two mechanisms of action appear to deliver contradictory and conflicting messages to the brain with respect to reward. Although tramadol is often listed with opioid agents, it is difficult to group it with the "classic opioids" as it has such important distinctions and, when used judiciously, the nonopioid component appears to be the major contributor to the analgesic effect.

- Tapentadol is likewise challenging to classify. It has a dual mechanism of action in a single molecule (unlike tramadol, which is a racemate) and with respect to analgesia, it has no active metabolites [48]. It has both an affinity for opioid receptors and contributes to noradrenergic activity in a synergistic way [49]. With its unique attributes, tapentadol has been classified an entirely new class of analgesic, although it is often listed as an opioid [50].

- Cebranopadol is a novel analgesic that acts as both an opioid agonist and also acts on nociception/orphanin FQ-peptide receptors [51]. This new agent may represent a new classification of drug. Further study will determine how best to categorize it, but it has marked distinctions from the traditional opioids.

\section{THE EFFECTIVENESS OF OPIOID ANALGESICS}

The World Health Organization pain ladder classified opioids as "weak" (e.g., codeine) or "strong" (e.g., morphine, oxycodone, and others) [16], but today such designations are less frequently used, with modern classifications based on mechanism of action (e.g., receptor binding profile) $[52,53]$. In addition to pharmacodynamic (PD) differences among opioids (e.g., receptor affinity), there are also pharmacokinetic (PK) differences (for instance, morphine is metabolized by different enzymatic pathways than is oxycodone) and sometimes large differences in patient response. Certain genetic polymorphisms (e.g., poor metabolizers or ultra-rapid metabolizers) may affect opioid metabolism to the extent that they may cause a response in the patient that is less than or more than the anticipated one. Genetic differences in patient response are particularly common with codeine, but may occur with other opioids as well [54-56]. It is for that reason that opioid rotation-changing from one opioid to another-can be helpful when a patient does not achieve the desired analgesic benefit from one product, as that patient may respond better to another opioid [57].

Opioids are effective pain relievers for a variety of painful conditions, including cancer pain, traumatic pain, postsurgical pain, and pain at end of life [58-62], but opioid analgesics are not equally effective for all types of pain. For example, opioids are not very effective and might be better avoided in the treatment of headaches, such as cluster headaches and migraines [63]. The long-term use of opioids for chronic noncancer pain remains controversial [64-67]. The role of opioid analgesics in the treatment of moderate to severe chronic noncancer pain has been advocated by specialty societies and is recognized as appropriate and valuable by many experts, but their use raises serious issues in light of opioid misuse and abuse [68-71].

With prolonged exposure to opioids, tolerance develops to some effects. Tolerance may be defined as the condition in which the patient requires a larger dose of opioids to maintain the same level of analgesic relief. Tolerance is not a dangerous, aberrant, or unexpected phenomenon; indeed, it is to be expected and may develop in as little as a few days [72]. Tolerance can be a troublesome phenomenon, as patients 
who seek more drugs are often suspected by healthcare providers of being drug-seekers. Indeed, a condition described as "pseudo-addiction" occurs when a tolerant patient is perceived as being an addict because the patient requests higher doses of opioids [73, 74]. Opioid tolerance occurs with both analgesic effect (necessitating higher doses to maintain equianalgesic effect) and certain adverse effects (but generally not constipation), which diminish over time as the patient builds up tolerance.

Patients may also become dependent on opioids. The term "dependence," similar to much of the terminology surrounding opioids, can be misleading. Physical dependence occurs with just a few days of sustained opioid consumption [75], manifested upon abrupt discontinuation ("abstinence-induced" withdrawal) by unpleasant and distressing withdrawal symptoms. Physical dependence is the normal compensatory response to the sustained use of an opioid and is neither aberrant or unexpected [76]. It may be clinically managed by having the patient taper off the drug gradually under medical supervision.

\section{SAFETY AND TOLERABILITY OF OPIOIDS}

Opioid-associated side effects are well described in the literature and may be divided into those that are transient in most patients and will remit as the patient develops tolerance (such as nausea and vomiting) and those that persist (such as constipation). The clinical response varies among patients; side effects may be transient in some patients but persist in others. Tolerance to opioid-associated side effects may also be categorized as innate (genetically predetermined and present from the initial dose) or acquired. Acquired tolerance to adverse effects may be due to a PK factor (e.g., drug metabolism), PD factor (e.g., upregulation or downregulation of opioid receptors), or even learned response (e.g., patient expectations may reduce effects over time) $[72,77]$. The side effects of opioids may be treatment limiting [78]. Thus, for pain management, it may be necessary for the clinician to manage opioid-associated side effects.

\section{Transient Side Effects}

Among the transient effects of opioids are nausea and vomiting, pruritus, sedation, respiratory depression (which can be life threatening), and urinary retention.

Nausea and Vomiting The emetogenic effects observed during opioid exposure are primarily derived from three major mechanisms: a direct effect on the chemoreceptor trigger zone (peripherally located outside of the blood-brain barrier in the area postrema within the brain's fourth ventricle), enhanced sensitivity of the vestibular apparatus (via activation of the MORs in the vestibular epithelium), and delayed gastric emptying mediated via both central and peripheral MORs [79]. Refractory and possibly opioid-induced constipation and stool impaction may contribute to nausea and vomiting. Nausea and vomiting occur in a subset of patients and typically resolve over time as the patient develops tolerance to these effects. For prophylactic management, a dopamine antagonist, such as metoclopramide (a prokinetic agent), or a serotonin receptor antagonist, such as ondansetron, are considered first-line therapies by some [80]. In certain cases, when nausea and vomiting are associated with vertigo, an anticholinergic drug, such as scopolamine, or an antihistamine, such as diphenhydramine, may be helpful [81].

Puritus Pruritus without skin lesions is a commonly reported adverse effect of opioid therapy [82]. It had been theorized that opioid-associated pruritus was related to the histamine release that occurs with morphine, but other opioid agents, such as fentanyl and oxymorphone, are not associated with histamine release, yet exhibit a similar incidence of pruritus [83]. Agonism at the MOR may be the cause of opioid-associated pruritus [84]. While the exact mechanism remains to be elucidated, antihistamines are often considered the first-line therapy, or a low-dose opioid antagonist, such as oral naltrexone, may be prescribed [85].

Sedation Sedation can be a particularly impactful adverse effect when considered in the setting of chronic opioid use, such as in treating 
cancer pain. It may negatively impact the quality of life and function. Typically, psychostimulants, such as methylphenidate or modafinil, are used to address sedation. While the evidence supporting the use of methylphenidate comes from randomized controlled trials and seems stronger than that from retrospective studies supporting modafinil, modafinil is a non-amphetamine stimulant that lacks some of the associated side effects typical of amphetamines, such as anxiety and tachycardia [86-89]. Other psychostimulants from various other drug classes, such as donepezil or caffeine, do not have the same evidence-based support of efficacy [89].

Respiratory Depression Although respiratory depression is a potentially lethal adverse effect of most opioids, tolerance is known to develop fairly rapidly, thus allowing for proper dosing when referenced with respect to common clinical guidelines [90]. When respiratory depression occurs as a result of opioid toxicity, an opioid receptor antagonist is most frequently used to reverse this effect [91]. It is also important to consider the possible synergistic effects on respiratory depression when other centrally acting agents, such as benzodiazepines, are used concomitantly with opioids [92]. Further, certain medical disease states, such as cancer, sleep apnea, chronic obstructive pulmonary disease, pneumonia, and other conditions, may have an impact on the patient's respiratory rate or tidal volume which may make the patient more vulnerable to respiratory distress and depression.

Urinary Retention Two main mechanisms have been proposed that might explain opioid-associated urinary retention. The first is the activation of opioid receptors in the spinal cord leading to bladder wall relaxation [93]. The second is that opioids affect the bladder sphincter and surrounding nerves by increasing parasympathetic input to the detrusor muscle and, in so doing, inhibit somatic impulses to the urethral sphincter [94]. A meta-analysis suggests that concomitant administration of a nonsteroidal anti-inflammatory drug (NSAID) may reduce the incidence of urinary retention, but this may be due to the net opioid-sparing effects of NSAID use, which reduces opioid-receptor activation [95]. Urinary retention can be treated using relatively benign therapies, like an $\alpha-1$ adrenoreceptor antagonist (e.g. tamsulosin).

\section{Persistent Side Effects}

Opioid-induced Constipation One of the most commonly reported and troublesome side effects of opioid use is opioid-induced constipation (OIC) [96]. OIC may occur in $45 \%$ of patients on chronic opioid therapy [97] and can adversely affect the patient's quality of life, productivity, and pain control [98]. It is perceived by patients to be one of the most distressing side effects, with the potential to limit opioid treatment, and can be a serious and costly adverse effect $[99,100]$. The mechanisms underlying OIC may be similar to those for urinary retention, namely, activation of opioid receptors in the enteric circuitry of the gastrointestinal (GI) tract inhibits gastric emptying, increases sphincter tone, induces stationary motor patterns, and blocks peristalsis. Combined with the antagonistic effects of opioids at the secretomotor neuron level of the enteric nervous system, such an action may prolong transit times and dehydrate the stool [101, 102]. Whether or not certain opioids produce less constipation than others has been the subject of some study, but exceeds the scope of our article [103-106]. While laxatives and other conventional constipation treatments may be employed, OIC may be laxative-refractory [107]. Peripherally acting MOR antagonist (PAMORA) agents, such as naloxegol and methylnaltrexone, may be helpful [108-111]. Combination drugs that incorporate an opioid + naltrexone may also be useful; a timed-release mechanism allows the antagonist (e.g., naltrexone) to be active as the drug passes through the GI system, but the antagonist is metabolized before the agonist enters the systemic circulation [112].

Endocrine Function Opioids may affect endocrine function because they bind to opioid receptors located within the hypothalamus and possibly with receptors in the pituitary gland and testes [113]. Binding at the hypothalamic level results in a decrease in gonadotropin-releasing 
hormone, which in turn leads to a decrease in luteinizing hormone and follicle-stimulating hormone at the level of the pituitary, which may result in hypogonadism. Hypogonadism is associated with decreased libido, disrupted menses, and impotence in males [114]. Once proper diagnosis has been made, the patient might be administered supplementary testosterone or estrogen and prolactin [115].

\section{MISUSE, ABUSE, AND ADDICTION}

Opioids activate dopaminergic neurons in the ventral tegmental area of the brain and, in that way, can produce a strong positive central reinforcement. Opioid use is perceived by many (but not all) individuals as pleasant, enjoyable, and even stimulating [116]. Because of the comparatively rapid rate at which tolerance can develop, individuals need higher and higher doses of opioids to achieve the same rewarding feelings or pleasant sensations. Just as higher doses are needed to maintain the same therapeutic efficacy, higher doses may be needed to achieve the same rewarding effect. Not all individuals find opioids pleasurable, but many do. Scientists and clinicians have developed ways of measuring this on scales of so-called "drug liking" [117]. While there can be considerable variation among individual drug abusers, general trends can be observed. Oxycodone, for example, is much more "liked" than buprenorphine. Actual abuse statistics reflect drug-liking in part, but can also be significantly impacted by such factors as local availability, prices, and access.

The inappropriate use of opioids is not just one behavior; inappropriate use exists along a broad continuum. In general, opioid misuse encompasses such relatively mild inappropriate behaviors such as not taking drugs as prescribed (skipping doses on good days and doubling up on bad days), chemical coping (taking opioids to manage stress or help improve mood), abuse (recreational use, taking opioids to get high), addiction, and diversion [118]. Some patients appear to be particularly vulnerable to inappropriately using opioids while others do not. Most patients prescribed opioids for pain control do not become addicted to them [119]_but some do. Many prescription opioid addicts never had a legitimate pain indication for the drugs. Thus, the population of those who use opioids inappropriately is heterogeneous and somewhat fluid [120]. While there is a lack of objective evidence that would firmly establish who becomes addicted and why, some risk factors have emerged along with demographic information about those who experience overdose:

- In a retrospective study of 2039 patients with at least one instance of opioid overdose, most were unemployed (78\%) and about one-third had mental health disorders (35\%) [121].

- Overdose is more likely to occur in people who live in rural rather than urban environments [122].

- Among the known risk factors that are associated with inappropriate use of opioids are younger age, male sex, a history of substance abuse, and mental health disorders [123]. However, opioid abuse occurs at older ages as well [121].

- Cigarette smokers, those who used nonopioid illicit drugs, and those with a history of prior arrest for breaking the law have higher probability of opioid abuse [124].

A variety of validated tools exist to help identify patients at elevated risk for opioid use, such as the Opioid Risk Tool (ORT) and the Screener and Opioid Assessment for Patients with Pain-Revised (SOAPP-R), among others [125]. It is important that patients be assessed periodically for their risk of opioid abuse, as risk factors may change over time [120]. While much is known about risk factors for opioid abuse, it is not possible to use such systems to positively determine that any one patient will definitely abuse or not abuse an opioid. Moreover, these risk factors only help define which legitimate pain patients are at risk for abuse and cannot help to prevent abuse by those who do not have contact with the healthcare system and start their drug misuse with drugs obtained in other ways (e.g., from friends, street dealers, etc.).

Addiction is the most severe form of inappropriate use of opioids and is the least 
understood. It is a complex biopsychosocial phenomenon that has contributing genetic and environmental factors [126]. Unlike patients who may be only physically dependent on opioids, addicts take opioids compulsively even when they fully understand that they are harming themselves [127]. Addiction is characterized by intense cravings for opioids that may not diminish even after the patient has undergone detoxification.

\section{HOW DOES OPIOID PHARMACOLOGY CONTRIBUTE TO ABUSE?}

Opioid abuse has occurred wherever and whenever opioids have been used [128]. There are many reasons for their appeal to abusers, and opioid pharmacology plays a major role in why and how they are abused.

First, opioids are very effective pain relievers. It has been speculated that some opioid abusers may be in pain (mental or physical) and use opioids to self-medicate. Since the fastest growing age group of those who misuse or abuse prescription opioids is the group aged 50-64 years and many painful conditions increase in prevalence with older age, it may be that some individuals are trying to manage pain [129]. The pain may also be psychological. Childhood trauma and abuse have been linked to substance abuse disorders, including opioid addiction [130]. Thus, opioid misuse may be a coping mechanism for certain individuals with psychological distress, unresolved emotional pain, stress, and mental health disorders, such as obsessive-compulsive disorder [131]. In other words, some opioid abuse may be misguided attempts at managing pain that cannot be handled any other or any better way.

Second, it may be that persistent pain and stress facilitate addiction in that they result in maladaptive disruptions to the body's neuronal and hormonal systems that, in turn, can affect the mesolimbic dopaminergic pathways. It is thought that the KOR system in particular is involved in some of these neuronal changes because it controls how dopamine is released into the nucleus accumbens. For example, chronic pain and stress can affect how the body perceives such things as food, social interaction, or drugs as a form of reward or coping mechanism. In this way, chronic pain itself may set the stage to make a patient more likely to perceive opioids as rewarding and thus addictive [132]. The mesolimbic dopamine circuit influences how responsive an individual will be to opioids and antidepressants [133]. It has also been theorized that for a person suffering pain, pain relief in and of itself is rewarding; that is, an individual experiences pain, takes an opioid analgesic, experiences profound relief, and interprets this as a positive, rewarding, pleasurable experience. This "reward" may cause neuronal adaptation that encourages the patient to continue taking opioids [134].

Finally, opioids may also produce feelings of pleasure, contentedness, and satisfaction in certain individuals. The role of opioids on social bonding in humans is a new field of study, but there is evidence that feelings of social connection may be enhanced by opioids and diminished by an opioid antagonist (e.g., naltrexone) [135]. Since feelings of human attachment and bonding are so crucial to feelings of happiness and connection, further study is needed to determine why opioid "liking" varies so markedly among individuals [136].

\section{ABUSE MITIGATION}

There is much that can be done in terms of how opioids are formulated, developed, marketed, distributed, and described to patients that may reduce the potential for abuse. First, certain opioid agents are associated with a lower potential for abuse than others. For example, buprenorphine is generally considered to have lower rates of abuse than oxycodone, although published comparisons suggest that they have equivalent clinical efficacy [38]. Tramadol (which is not a true classic opioid) is also less associated with abuse than other agents, likely due to its dual mechanisms of action [47].

Second, drug formulations can play an important role. In an effort to reduce opioid abuse, manufacturers have started to develop specific formulations designed to resist or deter abuse. These may include tablets that resist 
crushing or dissolving (so that the drug cannot be inhaled, smoked, or injected) or products that sequester the opioid in such a way that it cannot be extracted. Some abuse-deterrent formulations combine the active opioid agent with an antagonist, such as naltrexone (which would negate the effects of the opioid); if the drug is taken properly, the opioid is effective, but if the drug is tampered with, the naltrexone is released [137, 138]. The Food and Drug Administration has developed standards for abuse-deterrent formulations (ADFs) and encourages all future opioid analgesic agents to be formulated as an ADF [139].

Other strategies to help prevent abuse include patient education, prescriber education, prescription drug monitoring programs, patient-provider opioid contracts, and risk assessment (risk evaluation and mitigation strategies), among others.

\section{CONCLUSION}

Opioids are powerful and effective pain relievers that play an important role in pain management, particularly in patients suffering from moderate to severe pain. While opioids are a broad class of drugs, there are subtle and not-so-subtle differences among them. However, inappropriate opioid use ranges from mild forms of misuse to recreational use to outright addiction and represents a significant public health concern. While opioid pharmacology contributes to the potential for these drugs to be abused, steps can be taken to reduce potential abuse, including risk assessments of patients vulnerable to abuse, abuse-deterrent formulations, patient and prescriber education, and other efforts. This knowledge can inform the opioid discourse by providing the basic science foundation upon which the epidemiological, legal, and other factors can be objectively evaluated, interpreted, and discussed (debated).

\section{ACKNOWLEDGMENTS}

No funding or sponsorship was received for this study or publication of this article. All named authors meet the International Committee of Medical Journal Editors (ICMJE) criteria for authorship for this manuscript, take responsibility for the integrity of the work as a whole, and have given final approval to the version to be published.

Disclosures. Joseph Pergolizzi, Robert Raffa, Jo Ann LeQuang and Garrett Berger declare that they have no conflict of interest.

Compliance with Ethics Guidelines. This article does not contain any new studies with human or animal subjects performed by any of the authors.

Data Availability. Data sharing is not applicable to this article as no datasets were generated or analyzed during the current study.

Open Access. This article is distributed under the terms of the Creative Commons Attribution-NonCommercial 4.0 International License (http://creativecommons.org/licenses/ by-nc/4.0/), which permits any noncommercial use, distribution, and reproduction in any medium, provided you give appropriate credit to the original author(s) and the source, provide a link to the Creative Commons license, and indicate if changes were made.

\section{REFERENCES}

1. Manchikanti L, Helm S 2nd, Fellows B, et al. Opioid epidemic in the United States. Pain Physician. 2012;15[3 Suppl]:ES9-38.

2. Rudd RA, Aleshire N, Zibbell JE, Gladden RM. Increases in drug and opioid overdose deaths-United States, 2000-2014. MMWR Morb Mortal Wkly Rep. 2016;64(50-51):1378-82.

3. Substance Abuse and Mental Health Services Administration (SAMHSA). Results from the 2011 National Survey on Drug Use and Health: Summary of National Findings. 2012. http://www.samhsa. gov/data/NSDUH/2k11Results/NSDUHresults2011. pdf. Accessed 9 Aug 2013.

4. Jones CM. Heroin use and heroin use risk behaviors among nonmedical users of prescription opioid pain relievers-United States, 2002-2004 and 
2008-2010. Drug Alcohol Depend. 2013;132(1-2):95-100.

5. Karakula SL, Weiss RD, Griffin ML, Borges AM, Bailey AJ, McHugh RK. Delay discounting in opioid use disorder: differences between heroin and prescription opioid users. Drug Alcohol Depend. 2016;169:68-72.

6. Florence CS, Zhou C, Luo F, Xu L. The economic burden of prescription opioid overdose, abuse, and dependence in the United States, 2013. Med Care. 2016;54(10):901-6.

7. Manchikanti L, Boswell MV, Hirsch JA. Lessons learned in the abuse of pain-relief medication: a focus on healthcare costs. Expert Rev Neurother. 2013;13(5):527-43 (quiz 544).

8. Garde D. Trump is 'doubling down' on the opioid crisis with promises of expanded treatment. 2016. October 15, 2016: https://www.statnews.com/2016/ 10/15/trump-opioid-expanded-treatment/. Accessed 10 Dec 2016.

9. McDonald DC, Carlson K, Izrael D. Geographic variation in opioid prescribing in the U.S. J Pain. 2012;13(10):988-96.

10. Beaudoin FL, Banerjee GN, Mello MJ. State-level and system-level opioid prescribing policies: the impact on provider practices and overdose deaths, a systematic review. J Opioid Manag. 2016;12(2): 109-18.

11. Cleary J, Simha N, Panieri A, et al. Formulary availability and regulatory barriers to accessibility of opioids for cancer pain in India: a report from the Global Opioid Policy Initiative (GOPI). Ann Oncol ESMO. 2013;24[Suppl 11]:xi33-40.

12. Cleary J, De Lima L, Eisenchlas J, Radbruch L, Torode J, Cherny NI. Formulary availability and regulatory barriers to accessibility of opioids for cancer pain in Latin America and the Caribbean: a report from the Global Opioid Policy Initiative (GOPI). Ann Oncol ESMO. 2013;24[Suppl 11]:xi41-50.

13. Cleary J, Powell RA, Munene G, et al. Formulary availability and regulatory barriers to accessibility of opioids for cancer pain in Africa: a report from the Global Opioid Policy Initiative (GOPI). Ann Oncol ESMO. 2013;24[Suppl 11]:xi14-23.

14. Cleary J, Silbermann M, Scholten W, Radbruch L, Torode J, Cherny NI. Formulary availability and regulatory barriers to accessibility of opioids for cancer pain in the Middle East: a report from the Global Opioid Policy Initiative (GOPI). Ann Oncol ESMO. 2013;24[Suppl 11]:xi51-9.
15. Cleary J, Radbruch L, Torode J, Cherny NI. Formulary availability and regulatory barriers to accessibility of opioids for cancer pain in Asia: a report from the Global Opioid Policy Initiative (GOPI). Ann Oncol ESMO. 2013;24[Suppl 11]:xi24-32.

16. World Health Organization (WHO). WHO's pain ladder for adults. 1988. http://www.who.int/cancer/ palliative/painladder/en/. Accessed 7 May 2013.

17. Daher M. Pain relief is a human right. Asian Pac J Cancer Prev. 2010;11[Suppl 1]:97-101.

18. International Pain Summit of the International Association for the Study of Pain. Declaration of Montreal: declaration that access to pain management is a fundamental human right. J Pain Palliat Care Pharmacother. 2011;25(1):29-31.

19. Ossipov MH, Dussor GO, Porreca F. Central modulation of pain. J Clin Investig. 2010;120(11): 3779-87.

20. Fornasari D. Pain mechanisms in patients with chronic pain. Clin Drug Investig. 2012;32[Suppl 1]:45-52.

21. Inturrisi CE. Clinical pharmacology of opioids for pain. Clin J Pain. 2002;18[4 Suppl]:S3-13.

22. Raffa RB. On subclasses of opioid analgesics. Curr Med Res Opin. 2014;30(12):2579-84.

23. Zhang M, Wang $X$, Zhang D, et al. Orphanin FQ antagonizes the inhibition of $\mathrm{Ca}(2+)$ currents induced by mu-opioid receptors. J Mol Neurosci. $2005 ; 25(1): 21-7$.

24. Thompson GL, Lane JR, Coudrat T, Sexton PM, Christopoulos A, Canals M. Biased agonism of endogenous opioid peptides at the mu-opioid receptor. Mol Pharmacol. 2015;88(2):335-46.

25. Bannister K, Dickenson AH. What do monoamines do in pain modulation? Curr Opin Support Palliat Care. 2016;10(2):143-8.

26. Blier P. Crosstalk between the norepinephrine and serotonin systems and its role in the antidepressant response. J Psychiatry Neurosci. 2001;26[Suppl]:S3-10.

27. Pergolizzi JV Jr, Raffa RB, Taylor R Jr. Treating acute pain in light of the chronification of pain. Pain Manag Nurs. 2014;15(1):380-90.

28. Ballantyne JC, Mao J. Opioid therapy for chronic pain. New Engl J Med. 2003;349(20):1943-53.

29. Joo DT. Mechanisms of opioid tolerance: merging evidence and therapeutic implications. Can J Anaesth. 2007;54(12):969-76. 
30. Chang G, Chen L, Mao J. Opioid tolerance and hyperalgesia. Med Clin N Am. 2007;91(2):199-211.

31. Lynch ME. Antidepressants as analgesics: a review of randomized controlled trials. J Psychiatry Neurosci. 2001;26(1):30-6.

32. Mercer SL, Coop A. Opioid analgesics and P-glycoprotein efflux transporters: a potential systems-level contribution to analgesic tolerance. Curr Top Med Chem. 2011;11(9):1157-64.

33. Lalovic B, Kharasch E, Hoffer C, Risler L, Liu-Chen LY, Shen DD. Pharmacokinetics and pharmacodynamics of oral oxycodone in healthy human subjects: role of circulating active metabolites. Clin Pharmacol Ther. 2006;79(5):461-79.

34. Okura T, Hattori A, Takano Y, et al. Involvement of the pyrilamine transporter, a putative organic cation transporter, in blood-brain barrier transport of oxycodone. Drug Metab Dispos. 2008;36(10): 2005-13.

35. Raffa RB, Clark-Vetri R, Tallarida RJ, Wertheimer AI. Combination strategies for pain management. Expert Opin Pharmacother. 2003;4(10):1697-708.

36. Kenakin T, Christopoulos A. Signalling bias in new drug discovery: detection, quantification and therapeutic impact. Nat Rev Drug Discov. 2013;12(3): 205-16.

37. Raffa RB, Budd K. Buprenorphine-the unique opioid analgesic. Stuttgart: Georg Thieme Verlag; 2005.

38. Pergolizzi J, Aloisi AM, Dahan A, et al. Current knowledge of buprenorphine and its unique pharmacological profile. Pain Pract. 2010;10(5):428-50.

39. Lutfy K, Cowan A. Buprenorphine: a unique drug with complex pharmacology. Curr Neuropharmacol. 2004;2(4):395-402.

40. Cowan A. Buprenorphine: new pharmacological aspects. Int J Clin Pract Suppl. 2003;133:3-8 (discussion 23-24).

41. Cicero TJ, Ellis MS, Surratt HL, Kurtz SP. Factors contributing to the rise of buprenorphine misuse: 2008-2013. Drug Alcohol Depend. 2014;142: 98-104.

42. Canadian Agency for Drugs and Technologies in Health. Suboxone versus methadone for the treatment of opioid dependence: a review of the clinical and cost-effectiveness. Ottawa: Canadian Agency for Drugs and Technologies in Health. 2013.

43. Raffa RB. A novel approach to the pharmacology of analgesics. Am J Med. 1996;101(1A):40S-6S.
44. Nakajima K, Obata $H$, Iriuchijima N, Saito S. An increase in spinal cord noradrenaline is a major contributor to the antihyperalgesic effect of antidepressants after peripheral nerve injury in the rat. Pain. 2012;153(5):990-7.

45. Stein C. The control of pain in peripheral tissue by opioids. N Engl J Med. 1995;332(25):1685-90.

46. Raffa RB, Friderichs E, Reimann W, et al. Complementary and synergistic antinociceptive interaction between the enantiomers of tramadol. J Pharmacol Exp Ther. 1993;267(1):331-40.

47. Raffa RB. Basic pharmacology relevant to drug abuse assessment: tramadol as example. J Clin Pharm Ther. 2008;33(2):101-8.

48. Raffa RB, Buschmann H, Christoph T, et al. Mechanistic and functional differentiation of tapentadol and tramadol. Expert Opin Pharmacother. 2012;13(10): 1437-49.

49. Schroder $\mathrm{W}$, Tzschentke TM, Terlinden $\mathrm{R}$, et al. Synergistic interaction between the two mechanisms of action of tapentadol in analgesia. J Pharmacol Exp Ther. 2011;337(1):312-20.

50. Kress HG. Tapentadol and its two mechanisms of action: is there a new pharmacological class of centrally-acting analgesics on the horizon? Eur J Pain. 2010;14(8):781-3.

51. Linz K, Christoph T, Tzschentke TM, et al. Cebranopadol: a novel potent analgesic nociceptin/orphanin FQ peptide and opioid receptor agonist. J Pharmacol Exp Ther. 2014;349(3):535-48.

52. Raffa RB, Pergolizzi JV Jr. A modern analgesics pain 'pyramid'. J Clin Pharm Ther. 2014;39(1):4-6.

53. Marinangeli F, Ciccozzi A, Leonardis M, et al. Use of strong opioids in advanced cancer pain: a randomized trial. J Pain Symptom Manag. 2004;27(5):409-16.

54. Foster A, Mobley E, Wang Z. Complicated pain management in a CYP450 2D6 poor metabolizer. Pain Pract. 2007;7(4):352-6.

55. Haufroid V, Hantson P. CYP2D6 genetic polymorphisms and their relevance for poisoning due to amfetamines, opioid analgesics and antidepressants. Clin Toxicol (Phila). 2015;53(6):501-10.

56. Mikus G, Somogyi AA, Bochner F, Chen ZR. Polymorphic metabolism of opioid narcotic drugs: possible clinical implications. Ann Acad Med Singap. 1991;20(1):9-12.

57. Nalamachu SR. Opioid rotation in clinical practice. Adv Ther. 2012;29(10):849-63. 
58. National Comprehensive Cancer Network (NCCN). Adult cancer pain. NCCN clinical practice guidelines in oncology (NCCN guidelines) 2014; Version 2.2014. http://www.nccn.org/professionals/physician_gls/ PDF/pain.pdf. Accessed 4 July 2014.

59. Caraceni A. The EPCRC project to revise the European Association for Palliative Care (EAPC) guidelines on the use of opioids for cancer pain. Palliat Med. 2011;25(5):389-90.

60. Caraceni A, Davies A, Poulain P, Cortes-Funes H, Panchal SJ, Fanelli G. Guidelines for the management of breakthrough pain in patients with cancer. J Natl Compr Cancer Netw. 2013;11[Suppl 1]:S29-36.

61. Caraceni A, De Conno F, Kaasa S, Radbruch L, Hanks G. Update on cancer pain guidelines. J Pain Symptom Manag. 2009;38(3):e1-3.

62. Chou R. 2009 Clinical guidelines from the American Pain Society and the American Academy of Pain Medicine on the use of chronic opioid therapy in chronic noncancer pain: what are the key messages for clinical practice? Pol Arch Med Wewn. 2009;119(7-8):469-77.

63. Ansari H, Kouti L. Drug interaction and serotonin toxicity with opioid use: another reason to avoid opioids in headache and migraine treatment. Curr Pain Headache Rep. 2016;20(8):50.

64. Stein C, Baerwald C. Opioids for the treatment of arthritis pain. Expert Opin Pharmacother. 2014;15(2):193-202.

65. Watson CP. Opioids in chronic noncancer pain: more faces from the crowd. Pain Res Manag. 2012;17(4):263-75.

66. Cheatle MD, O'Brien CP. Opioid therapy in patients with chronic noncancer pain: diagnostic and clinical challenges. Adv Psychosom Med. 2011;30: 61-91.

67. Stein C, Reinecke H, Sorgatz H. Opioid use in chronic noncancer pain: guidelines revisited. Curr Opin Anaesthesiol. 2010;23(5):598-601.

68. Zhang W, Doherty M, Arden N, et al. EULAR evidence based recommendations for the management of hip osteoarthritis: report of a task force of the EULAR Standing Committee for International Clinical Studies Including Therapeutics (ESCISIT). Ann Rheum Dis. 2005;64(5):669-81.

69. Zhang W, Doherty M, Bardin T, et al. EULAR evidence based recommendations for gout. Part II: management. Report of a task force of the EULAR Standing Committee for International Clinical
Studies Including Therapeutics (ESCISIT). Ann Rheum Dis. 2006;65(10):1312-24.

70. Zhang W, Doherty M, Leeb BF, et al. EULAR evidence based recommendations for the management of hand osteoarthritis: report of a Task Force of the EULAR Standing Committee for International Clinical Studies Including Therapeutics (ESCISIT). Ann Rheum Dis. 2007;66(3):377-88.

71. Zhang W, Moskowitz RW, Nuki G, et al. OARSI recommendations for the management of hip and knee osteoarthritis, Part II: OARSI evidence-based, expert consensus guidelines. Osteoarthr Cartil. 2008;16(2):137-62.

72. Collett B-J. Opioid tolerance: the clinical perspective. Br J Anaesth. 1998;81:58-68.

73. Weissman DE, Haddox JD. Opioid pseudoaddictionan iatrogenic syndrome. Pain. 1989;36(3):363-6.

74. Bell K, Salmon A. Pain, physical dependence and pseudoaddiction: redefining addiction for 'nice' people? Int J Drug Policy. 2009;20(2):170-8.

75. Miyoshi H, Leckband S. Bonica's management of pain. Philadelphia: Lippincott Williams \& Wilkins; 2001.

76. Kirsh KL, Whitcomb LA, Donaghy K, Passik SD. Abuse and addiction issues in medically ill patients with pain: attempts at clarification of terms and empirical study. Clin J Pain. 2002;18[4 Suppl]:S52-60.

77. Cepeda-Benito A, Davis K, Harraid J. Associative and behavioral tolerance to the analgesic effects of nicotine in rats: tail flick and paw-lick assays. Psychopharmacology. 2005;180:224-33.

78. Manchikanti L, Abdi S, Atluri S, et al. American Society of Interventional Pain Physicians (ASIPP) guidelines for responsible opioid prescribing in chronic non-cancer pain: Part 2-guidance. Pain Physician. 2012;15[3 Suppl]:S67-116.

79. Smith HS, Smith JM, Seidner P. Opioid-induced nausea and vomiting. Ann Palliat Med. 2012;1(2):121-9.

80. Laugsand E, Fladvad T, Skorpen F, et al. Clinical and genetic factors associated with nausea and vomiting in cancer patients receiving opioids. Eur J Cancer Care. 2011;47:1682-91.

81. Pergolizzi JV Jr, Philip BK, Leslie JB, Taylor R Jr, Raffa RB. Perspectives on transdermal scopolamine for the treatment of postoperative nausea and vomiting. J Clin Anesth. 2012;24(4):334-45.

82. Ebata T. Drug-induced itch management. Curr Probl Dermatol. 2016;50:155-63. 
83. Hermens J, Ebertz J, Hanifin J, Hirshman C. Comparison of histamine release in human skin mast cells induced by morphine, fentanyl, and oxymorphone. Anesthesiology. 1985;62(2):124-9.

84. Ko MC. Neuraxial opioid-induced itch and its pharmacological antagonism. Handb Exp Pharmacol. 2015;226:315-35.

85. Ganesh A, Maxwell L. Pathophysiology and management of opioid-induced pruritus. Drugs. 2007;67(16):2323-33.

86. Bruera E, Miller M, Macmillan K, Kuehn N. Neuropsychological effects of methylphenidate in patients receiving a continuous infusion of narcotics for cancer pain. Pain. 1992;48(2):163-6.

87. Wilwerding MB, Loprinzi CL, Mailliard JA, et al. A randomized, crossover evaluation of methylphenidate in cancer patients receiving strong narcotics. Support Care Cancer. 1995;3(2):135-8.

88. Webster L, Andrews M, Stoddard G. Modafinil treatment of opioid-induced sedation. Pain Med. 2003;4(2):135-40.

89. Stone P, Minton O. European Palliative Care Research collaborative pain guidelines. Central side-effects management: what is the evidence to support best practice in the management of sedation, cognitive impairment and myoclonus? Palliat Med. 2011;25(5):431-41.

90. Nuckols TK, Anderson L, Popescu I, et al. Opioid prescribing: a systematic review and critical appraisal of guidelines for chronic pain. Ann Intern Med. 2014;160(1):38-47.

91. Neumar RW, Shuster M, Callaway CW, et al. Part 1: Executive summary: 2015 American Heart Association guidelines update for cardiopulmonary resuscitation and emergency cardiovascular care. Circulation. 2015;132[18 Suppl 2]:S315-67.

92. Jones JD, Mogali S, Comer SD. Polydrug abuse: a review of opioid and benzodiazepine combination use. Drug Alcohol Depend. 2012;125(1-2):8-18.

93. Al-Hasani R, Bruchas MR. Molecular mechanisms of opioid receptor-dependent signaling and behavior. Anesthesiology. 2011;115(6):1363-81.

94. Verhamme KM, Sturkenboom MC, Stricker BH, Bosch R. Drug-induced urinary retention: incidence, management and prevention. Drug Saf Drug Exp. 2008;31(5):373-88.

95. Marret E, Kurdi O, Zufferey P, Bonnet F. Effects of nonsteroidal antiinflammatory drugs on patient-controlled analgesia morphine side effects: meta-analysis of randomized controlled trials. Anesthesiology. 2005;102(6):1249-60.

96. Webster LR. Opioid-induced constipation. Pain Med. 2015;16[Suppl 1]:S16-21.

97. Bell TJ, Panchal SJ, Miaskowski C, Bolge SC, Milanova T, Williamson R. The prevalence, severity, and impact of opioid-induced bowel dysfunction: results of a US and European Patient Survey (PROBE 1). Pain Med. 2009;10(1):35-42.

98. Bell T, Annunziata K, Leslie JB. Opioid-induced constipation negatively impacts pain management, productivity, and health-related quality of life: findings from the National Health and Wellness Survey. J Opioid Manag. 2009;5(3):137-44.

99. Hess B, Bernardi M, Klotz HP. Attitude of Swiss physicians towards opioid-induced constipation: a national survey. Eur J Intern Med. 2011;22(5):527-31.

100. Hjalte F, Berggren AC, Bergendahl H, Hjortsberg C. The direct and indirect costs of opioid-induced constipation. J Pain Symptom Manag. 2010;40(5):696-703.

101. Holzer P. Opioid receptors in the gastrointestinal tract. Regul Pept. 2009;155(1-3):11-7.

102. Wood JD, Galligan JJ. Function of opioids in the enteric nervous system. Neurogastroenterol Motil. 2004;16[Suppl 2]:17-28.

103. Tassinari D, Sartori S, Tamburini E, et al. Adverse effects of transdermal opiates treating moderate-severe cancer pain in comparison to long-acting morphine: a meta-analysis and systematic review of the literature. J Palliat Med. 2008;11(3):492-501.

104. Kokki M, Kuronen M, Naaranlahti T, et al. Opioid-induced bowel dysfunction in patients undergoing spine surgery: comparison of oxycodone and oxycodone-naloxone treatment. Adv Ther. 2017;34(1):236-51

105. Viscusi ER, Grond S, Ding L, Danesi H, Jones JB, Sinatra RS. A comparison of opioid-related adverse events with fentanyl iontophoretic transdermal system versus morphine intravenous patient-controlled analgesia in acute postoperative pain. Pain Manag. 2016;6(1):19-24.

106. Pergolizzi JV Jr, Scholten W, Smith KJ, Leighton-Scott J, Willis JC, Henningfield JE. The unique role of transdermal buprenorphine in the global chronic pain epidemic. Acta Anaesthesiol Taiwan. 2015;53(2):71-6.

107. Tarumi Y, Wilson MP, Szafran O, Spooner GR. Randomized, double-blind, placebo-controlled trial 
of oral docusate in the management of constipation in hospice patients. J Pain Symptom Manag. 2013;45(1):2-13.

108. Anantharamu T, Sharma S, Gupta AK, Dahiya N, Singh Brashier DB, Sharma AK. Naloxegol: first oral peripherally acting mu opioid receptor antagonists for opioid-induced constipation. J Pharmacol Pharmacother. 2015;6(3):188-92.

109. Li Z, Pergolizzi JV, Huttner RP, Zampogna G, Breve F, Raffa RB. Management of opioid-induced constipation in pregnancy: a concise review with emphasis on the PAMORAs. J Clin Pharm Ther. 2015;40(6):615-9.

110. Diego L, Atayee R, Helmons P, Hsiao G, von Gunten CF. Novel opioid antagonists for opioid-induced bowel dysfunction. Expert Opin Investig Drugs. 2011;20(8):1047-56.

111. Belavic JM. Methylnaltrexone for opioid-induced constipation. Nurse Pract. 2009;34(3):6-7.

112. Davis M, Goforth HW, Gamier P. Oxycodone combined with opioid receptor antagonists: efficacy and safety. Expert Opin Drug Saf. 2013;12(3):389-402.

113. Katz N, Mazer N. The impact of opioids on the endocrine system. Clin J Pain. 2009;25:170-5.

114. Birthi P, Nagar VR, Nickerson R, Sloan PA. Hypogonadism associated with long-term opioid therapy: A systematic review. J Opioid Manag. 2015;11(3): 255-78.

115. Colameco S, Coren J. Opioid-induced endocrinopathy. J Am Osteopath Assoc. 2009;109:20-5.

116. Walsh SL, Nuzzo PA, Lofwall MR, Holtman JR Jr. The relative abuse liability of oral oxycodone, hydrocodone and hydromorphone assessed in prescription opioid abusers. Drug Alcohol Depend. 2008;98(3):191-202.

117. Pergolizzi JV, Raffa RB, Pergolizzi JS, Taylor R. Non-analgesic effects of opioids: factors relevant to opioid abuse and abuse-deterrent formulations. Curr Pharm Des. 2012;18(37):6109-15.

118. Garland EL, Froeliger B, Zeidan F, Suveg K, Howard MO. The downward spiral of chronic pain, prescription opioid misuse, and addiction: cognitive, affective, and neuropsychopharmacologic pathways. Neurosci Biobehav Rev. 2013; 37(10). doi:10. 1016/j.neubiorev.2013.08.006.

119. Cheatle MD. Prescription opioid misuse, abuse, morbidity, and mortality: balancing effective pain management and safety. Pain Med. 2015;16[Suppl 1]:S3-8.
120. Pergolizzi JV Jr, Gharibo C, Passik S, et al. Dynamic risk factors in the misuse of opioid analgesics. J Psychosom Res. 2012;72(6):443-51.

121. Boscarino JA, Kirchner HL, Pitcavage JM, et al. Factors associated with opioid overdose: a 10-year retrospective study of patients in a large integrated health care system. Subst Abus Rehabil. 2016;7:131-41.

122. Dunn KE, Barrett FS, Yepez-Laubach C, et al. Opioid overdose experience, risk behaviors, and knowledge in drug users from a rural versus an urban setting. J Subst Abus Treat. 2016;71:1-7.

123. Peck KR, Ehrentraut JH, Anghelescu DL. Risk factors for opioid misuse in adolescents and young adults with focus on oncology setting. J Opioid Manag. 2016;12(3):205-16.

124. Ihongbe TO, Masho SW. Prevalence, correlates and patterns of heroin use among young adults in the United States. Addict Behav. 2016;63:74-81.

125. Dale R, Edwards J, Ballantyne J. Opioid risk assessment in palliative medicine. J Commun Support Oncol. 2016;14(3):94-100.

126. American Society of Addiction Medicine. Definition of addiction. Qual Pract. 2016. http://www.asam. org/quality-practice/definition-of-addiction. Accessed 26 April 2016.

127. Katz N, Adams E, Benneyan J, et al. Foundations of opioid risk management. Clin J Pain. 2007;23:103-18.

128. Ahlbeck K. Opioids: a two-faced Janus. Curr Med Res Opin. 2011;27(2):439-48.

129. Chang YP, Compton P. Opioid misuse/abuse and quality persistent pain management in older adults. J Gerontol Nurs. 2016;42(12):21-30.

130. Kristjansson S, McCutcheon VV, Agrawal A, et al. The variance shared across forms of childhood trauma is strongly associated with liability for psychiatric and substance use disorders. Brain Behav. 2016;6(2):e00432.

131. Peles E, Adelson M, Seligman Z, Bloch M, Potik D, Schreiber S. Psychiatric comorbidity differences between women with history of childhood sexual abuse who are methadone-maintained former opiate addicts and non-addicts. Psychiatry Res. 2014;219(1):191-7.

132. Massaly N, Moron JA, Al-Hasani R. A trigger for opioid misuse: chronic pain and stress dysregulate the mesolimbic pathway and kappa opioid system. Front Neurosci. 2016;10:480. 
133. Mitsi V, Zachariou V. Modulation of pain, nociception, and analgesia by the brain reward center. Neuroscience. 2016;338:81-92.

134. Navratilova E, Morimura K, Xie JY, Atcherley CW, Ossipov MH, Porreca F. Positive emotions and brain reward circuits in chronic pain. J Comp Neurol. 2016;524(8):1646-52.

135. Inagaki TK, Ray LA, Irwin MR, Way BM, Eisenberger NI. Opioids and social bonding: naltrexone reduces feelings of social connection. Soc Cogn Affect Neurosci. 2016;11(5):728-35.

136. Setnik B, Roland CL, Pixton G, Webster L. Measurement of drug liking in abuse potential studies: a comparison of unipolar and bipolar visual analog scales. J Clin Pharmacol. 2016; 57(2):266-74.
137. Pergolizzi JV Jr, LeQuang JA. Abuse-deterrent formulations of opioid analgesics. Pain Pract. 2014;14(3):204-6.

138. Ruan X. Sustained-release morphine sulfate with sequestered naltrexone for moderate to severe pain: a new opioid analgesic formulation and beyond. Expert Opin Pharmacother. 2011;12(7):999-1001.

139. Federal Drug Administration (FDA). Guidance for Industry: abuse-deterrent opioids, evaluation and labeling. 2013. http://www.fda.gov/downloads/ Drugs/GuidanceComplianceRegulatoryInformation/ Guidances/UCM334743.pdf. Accessed 25 April 2013. 